\title{
Speed control of induction motor with broken bars using sliding mode control (SMC) based to on type-2 fuzzy logic controller (T2FLC)
}

\author{
Djameleddine. Djafar*, Saad. Belhamdi \\ Electrical Engineering Laboratory, University Mohamed Boudiaf- Msila, Algeria
}

Corresponding Author Email: djafar.djameleddine@univ-msila.dz

https://doi.org/10.18280/ama_c.730409

Received: 8 July 2018

Accepted: 15 November 2018

\section{Keywords:}

induction motor, type-2 fuzzy logic speed controller, sliding mode control, broken bar, robustness

\begin{abstract}
The traditional control of induction motor is not enough, because it lacks robustness, especially when the demand for accuracy and other dynamic characteristics of the system are of better performance in nowadays industry. One of the most spreader problems of the induction motor that limits the performance of the speed control is the broken rotor bars. For Improving performance of the induction motor of broken rotor bars, sliding mode control based on fuzzy logic type-2 is analyzed within this research paper. Fuzzy logic is one of the methods that relay on artificial intelligence, and which does not require a mathematical model of the system as the traditional control does. Artificial intelligence is the most used one, especially when it comes to non-linear systems as the motor drive one.
\end{abstract}

\section{INTRODUCTION}

The growing demands for advanced induction motors that guarantee or ensure better robustness and low maintenance is increasing in our actual times, thus such type of motors is needed in industry and also in high techno domains, because they have a high power, and they are of low prices. But induction motor may face some disturbances such as: electrical and mechanical faults [1,3] as: broken bars, short circuits etc.

Developments in power electronics, theories of control and electrical techniques led to the use of Induction Motors which are of high performance, this use might face some difficulties because of factors as: non-linearity, complex and multivariable of mathematical order, these previous mentioned hinders did not exist with the Direct Current motors [2].

Sliding Mode Control is one of the methodologies, that recently have become the main operational mode [4], that are found in industrial applications like: electrical drives. This interest is related to facts as: the non-linearity, the robustness, and its capacity of reaching the upper limits during the minimum time. $[3,5]$.

Many researchers have proposed several techniques for achieving good performance of the Induction Motors, Fuzzy Logic Control is one of these, which is seen as the most used application [13] [7], when designing robust controllers, that can give or produce acceptable performance, especially in cases of uncertainty or imprecision's, more than this, Fuzzy Logic Controller provides a method, which is able in constructing controller algorithms, that are human like.[8]

In 1973, the first decision for establishing a Fuzzy Logic Control was proposed by Zedah, and was developed later on by Mamdani and Assilian in 1974 [9]. In contrast to, Type-1 Fuzzy logics Controls, which were characterized by the inability of fully handling or accommodating linguistic and numerical uncertainties, and the use of precise type-1 sets only,
Type-2 Fuzzy Logic Controls are: able to handle both linguistic and numerical uncertainties.

The reduction of the Fuzzy Logic rules base, and others that are of extra degrees Simulation results were made to show the effectiveness of the proposed control techniques the rest of the paper is divided into five sections, section two is about Modeling of the Induction Motor, and section three is going to describe the Sliding Mode Control of Induction Motor, section four is devoted to talk about the use of Type-2 Fuzzy Logic Control for Induction Motor, then the last section portrays simulation results, finishing by the conclusion.

\section{MODEL WITH FAULT OF INDUCTION MOTOR FOR ITS CONTROL}

In order to develop approaches which guarantee the targeted performance, we need a model that can reflect the machine's operation, and accounts for defective rotor (broken bars) [10]. For gaining this model, an approach that is consisted of modeling the machines rotor using Kirchhoff laws, which include circuits that are electrically and magnetically related with one another, The Induction Motor's mathematical model can be stated as follow:

$[L] \frac{d[I]}{d t}=[V]-[R][I]$

where:

$[L]=\left[\begin{array}{ccccc}L_{s c} & 0 & -\frac{N_{r}}{2} M_{s r} & 0 & 0 \\ 0 & L_{s c} & 0 & -\frac{N_{r}}{2} M_{s r} & 0 \\ -\frac{3}{2} M_{s r} & 0 & L_{r c} & 0 & 0 \\ 0 & -\frac{3}{2} M_{s r} & 0 & L_{r c} & 0 \\ 0 & 0 & 0 & 0 & L_{e}\end{array}\right]$;


$[R]=\left[\begin{array}{ccccc}R_{s} & -\omega L_{s c} & 0 & \frac{N_{r}}{2} \omega M_{s r} & 0 \\ \omega L_{s c} & R_{s} & \frac{N_{r}}{2} \omega M_{s r} & 0 & 0 \\ 0 & 0 & R_{r d d} & R_{r d q} & 0 \\ 0 & 0 & R_{r q d} & R_{r q q} & 0 \\ 0 & 0 & 0 & 0 & R_{e}\end{array}\right]$

This equation shows the application of summation over all faulty bars.

$$
\begin{aligned}
& R_{r d d, r q q}=R_{r}+\frac{2}{N_{r}}(1-\cos \alpha) \sum_{k} R_{b f k} \cdot(1 \pm \cos (2 k-1) \cdot \alpha) \\
& R_{r d q, r q d}=-\frac{2}{N_{r}}(1-\cos \alpha) \sum_{k} R_{b f k} \cdot \sin (2 k-1) \cdot \alpha
\end{aligned}
$$

The electromagnetic torques expression is given as bellow:

$C_{e}=\frac{3}{2} p\left(\Phi_{d s} I_{q s}-\Phi_{q s} I_{d s}\right)$

The tension expression of the machine is given like this: [11]

$$
\left\{\begin{array}{c}
V_{d s}=R_{s} I_{d s}+\frac{d \Phi_{d s}}{d t}-\omega_{s} \Phi_{q s} \\
V_{q s}=R_{s} I_{q s}+\frac{d \Phi_{q s}}{d t}+\omega_{s} \Phi_{d s} \\
0=R_{r} I_{d r}+\frac{d \Phi_{d r}}{d t}-\omega_{r} \Phi_{q r} \\
0=R_{r} I_{q r}+\frac{d \Phi_{q r}}{d t}+\omega_{r} \Phi_{d r}
\end{array}\right.
$$

When applying field oriented control strategy, the $d$ axis is oriented in accord with the axis of the rotor flux, and it follows this:

$$
\left\{\begin{array}{c}
\Phi_{d r}=\Phi_{r}=\text { constant } \\
\Phi_{q r}=0
\end{array}\right.
$$

The application of (4 and 6) results of the oriented control, results in the following torque equation:

$C_{e}=\frac{3}{2} p \cdot \frac{M}{L_{r c}} \Phi_{r} I_{q s}$

Then, the dynamic equation (5) is this way:

$$
\left\{\begin{array}{c}
V_{d s}=\left(R_{s}+s \cdot \sigma \cdot L_{s c}\right) I_{d s}-\omega_{s} \cdot \sigma \cdot L_{s c} \cdot I_{q s} \\
V_{q s}=\left(R_{s}+s \cdot \sigma \cdot L_{s c}\right) I_{q s}+\omega_{s} \frac{M}{L_{r c}} \Phi_{r}+\omega_{s} \cdot \sigma \cdot L_{s c} \cdot I_{d s}
\end{array}\right.
$$

With: $\Phi_{r}=\frac{M}{1+s \cdot T_{r}} \cdot I_{d s} \quad ; \omega_{r}=\frac{M}{T_{r} \cdot \Phi_{r}} \cdot I_{q s}$

\section{SLIDING MODE CONTROL FOR THE INDUCTION MACHINE}

The Sliding Mode Control, has become a methodology that is the most used for the control system, it is based on variable structure control, and works on enforcing the motion of the Sliding Mode in previously defined switching surfaces using discontinuous control [4].

Sliding Mode Control has two main steps:

- In the first step, the switching surface is designed to produce the desired behavior.

- In the second one, the discontinuous control enforces the system to move on the sliding surface in a precise time.

The system behavior does not get affected by any modeling uncertainties and/ or disturbances in Sliding Mode [13].

The design of control system, takes a non-linear system, and is indicated as bellow: [12]

$\dot{x}(t)=f(x, t)+B(x, t) u(x, t)$

where $x \in \mathfrak{R}^{n}$ is the state vector, $f(x, t) \in \mathfrak{R}^{n}, B(x, t) \in$ $R^{n \times m}$ and $u \in R^{m}$ is the control vector.

From the system (9), it is possible for defining a set of the state trajectories like:

$S=\{x(t) ; \sigma(x, t)=0\}$

where: $\sigma(x, t)=\left[\sigma_{1}(x, t), \sigma_{2}(x, t), \ldots \ldots, \sigma_{n}(x, t)\right]^{T}$

The Sliding Mode must be well selected, in a way that the Lyapunov function satisfies the Lyapunov stability criteria:

$\left\{\begin{array}{l}V(x)=\frac{1}{2} \sigma^{2}(x) \\ \dot{\sigma}(x) \cdot \sigma(x) \prec 0\end{array}\right.$

The control function will be satisfying, so that it reaches conditions in the following from:

$U(t)=U_{e q}+U_{n}$

$U_{n}=-K \cdot \operatorname{sgn}(\sigma(x, t))$

where $\mathrm{U}$ is the control vector, $U_{e q}$ is the equivalent control vector, $U_{n}$ is the correction vector, $K$ is the controller gain, when the condition for the sliding regimen $\sigma(x, t)=0$ is considered $U_{e q}$ can be obtained. The state variable is kept on the sliding surface, when it is reached [10].

For defined signum function:

$\operatorname{sgn}(\varphi)=\left\{\begin{array}{cl}1 & \text { if } \varphi \succ 0 \\ 0 & \text { if } \varphi=0 \\ -1 & \text { if } \varphi \prec 0\end{array}\right.$ 


\section{ORDER BY TYPE-2 FUZZY LOGIC}

\section{a. Principe of a fuzzy controller}

The fuzzy logic's control allows us obtain a low of drive, that is characterized by being effective without having a precise model of the process.

Its approach is unlike the automatic classic one, thus it does not make use of mathematical relations, rather than this, and it utilizes the expert's knowledge. [10]

The fuzzy logic controller is a rule based one, and its rules are of: "if _then "format. e g: If error is $\alpha_{i}$, and change in error is $\beta_{i}$, then output is $\phi_{i}$.

\section{b. Interval Type-2 Fuzzy Logic Control}

The traditional type-1 Fuzzy Logic Controller cannot handle with uncertainties, but a Fuzzy logic type-2 can, also it can provide better performance, in addition to its ability of overcoming limitations of the previous type (type-1) [8], more than this, the two types differ in two essential points related to the design, which are: the membership functions shape, and the output processer [11].

The Fuzzy Logic type-2 is composed of mainly five components, which are: Fuzzifier, Inference engine, Rule base, Type reducer and defuuzzifier [8].

The architecture of type-2 Fuzzy logic is shown in figure1:

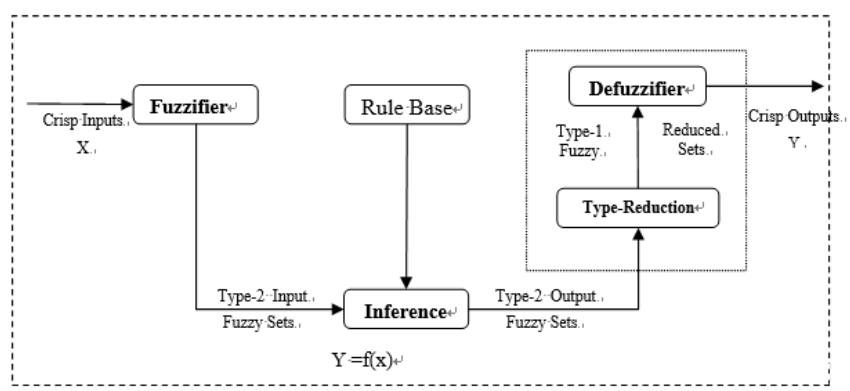

Figure 1. Block diagram of a type-2 FLC

Each pre-mentioned component has a role as in dictated bellow:

- Fuzzifier: works on translating inputs (real values) into fuzzy values.

- Inference engine: applies a fuzzy reasoning mechanism for obtaining a fuzzy output.

- Type defuzzifier / reducer: the translation of one input is into precise values is done by the defuzzifier, and the type reducer transforms type- 2 fuzzy sets into type-1 fuzzy set.

- Rule base: includes a set of fuzzy rules, and a membership functions set, called "the data base".

\section{c. Design of type-2 fuzzy logic mode control}

This paper is about the application of type-2 Fuzzy Logic for controlling the value of parameter, there are two input linguistic variables: which is population diversity $P D \in$ $[-0.02 ; 0.02]$ which is represented in type-2 fuzzy sets Figure 2.a In the proposed type-2 Fuzzy Logic Control membership function for output linguistic variable, this output variable is the $\alpha(\alpha \in[-10 ; 10])$ as indicated in Figure 2.b.
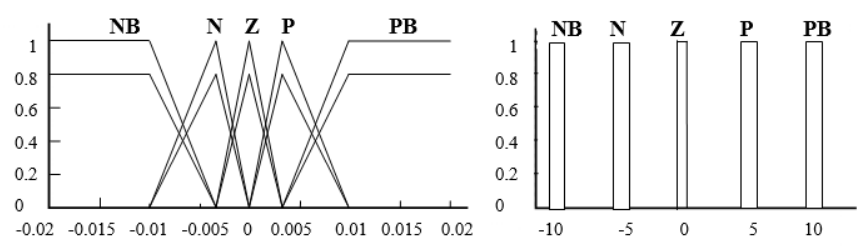

a: the input linguistic value

b: the output linguistic value

Figure 2. Graphical representation of fuzzy sets which represent

There are 25 Fuzzy rules, which determine the relation between input linguistic variables and output linguistic variables, the control rules are shown in Table 1.

Table 1. Fuzzy rule for type-2 FLC

\begin{tabular}{ccccccc}
\hline & & \multicolumn{5}{c}{$\mathbf{e}$} \\
\cline { 3 - 7 } & & NB & N & Z & P & PB \\
\hline \multirow{4}{*}{ De } & NB & NB & NB & N & N & Z \\
& N & NB & N & N & Z & PB \\
& Z & N & N & Z & P & PB \\
& P & N & Z & P & P & PB \\
& PB & Z & P & P & PB & PB \\
\hline
\end{tabular}

The fuzzy sets are defined as follow:

$\mathrm{NB}=$ Negative Big $\quad \mathrm{N}=$ Negative $\mathrm{Z}=$ Zero $\quad \mathrm{P}=$ Positive $\mathrm{PB}=$ Positive $\mathrm{Big}$

The Fuzzy sliding Mode Controller that is mentioned here is the modification of the sliding mode control equation (12), where a fuzzy control input replaces the switching term-K. $\operatorname{sgn}(\phi)$, as bellow:

$\left\{\begin{array}{c}U(t)=U_{e q}+U_{f u z z y} \\ U_{f u z z y}=-K_{f u z z y} \cdot \operatorname{sgn}(\varphi)\end{array}\right.$

The gain, $K_{f u z z}$ of the controller is determined from fuzzy rules.

The speed control block by the sliding mode control using regulator fuzzy type-2 is shown in Figure 3.

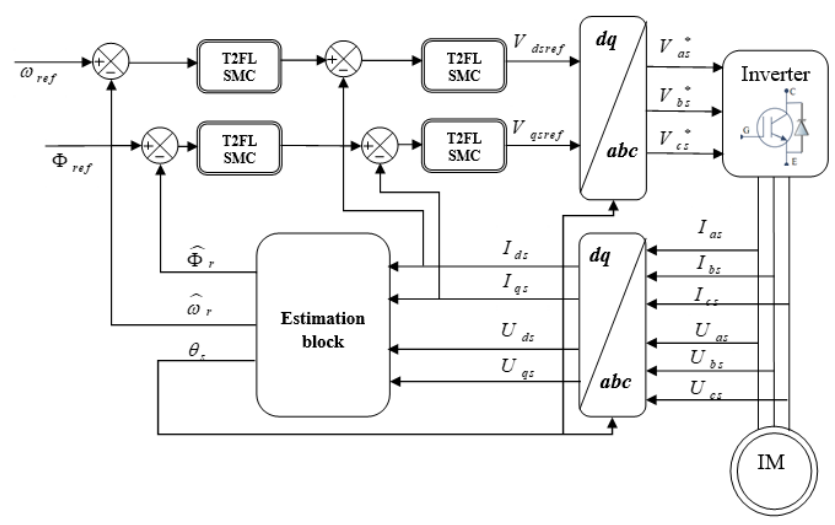

Figure 3. Block diagram of sliding mode control using regulator fuzzy logic type-2 


\section{RESULTS AND DISCUSSION}

The simulation is done using MATLAB and results are presented here, the motor used in the simulation study is a $1.1 \mathrm{Kw}$ cage rotor, $220 \mathrm{~V}, 50 \mathrm{HZ}$. The parameters of the IM are summarized in Appendix. In the following test, we use the classical discontinuous control defined by:

$-K \cdot \operatorname{sgn}(\phi)$, where $\mathrm{K}$ is a positive constant.

Figures 4 shows the speed response, torque, current stator and speed of fuzzy type-2 sliding mode controller when the machine is operated at $140[\mathrm{rd} / \mathrm{sec}]$ under no load and a nominal load disturbance torque ( $3.5 \mathrm{~N} . \mathrm{m})$ is suddenly applied at $1 \mathrm{sec}$. This is due to the facts that the fuzzy type-2 sliding mode control is a nonlinear control and the IM motor mathematical model is also non-linear and complex. Each rotor fault was modeled as a full broken rotor bar. The squirrelcage rotor of the tested IM consists of 16 bars. At $t=1.5 \mathrm{~s}$ we simulate a first broken bar, this is achieved by increasing its resistance, we only notice small oscillations on the speed. The second bar is broken a $\mathrm{t}=3 \mathrm{~s}$. The FL2SMC controller performed better performance with respect to rise time and steady state error. It can be seen that the proposed fuzzysliding mode control has the best response avoiding the overshoot and the chattering in steady-state operation. From simulation results it was shown that the proposed Fuzzy type2-Sliding Mode Controller is robust to external variations (broken bar) and has given satisfactory performances in speed response with no overshoot, rapid time response error and a good tracking reference speed.
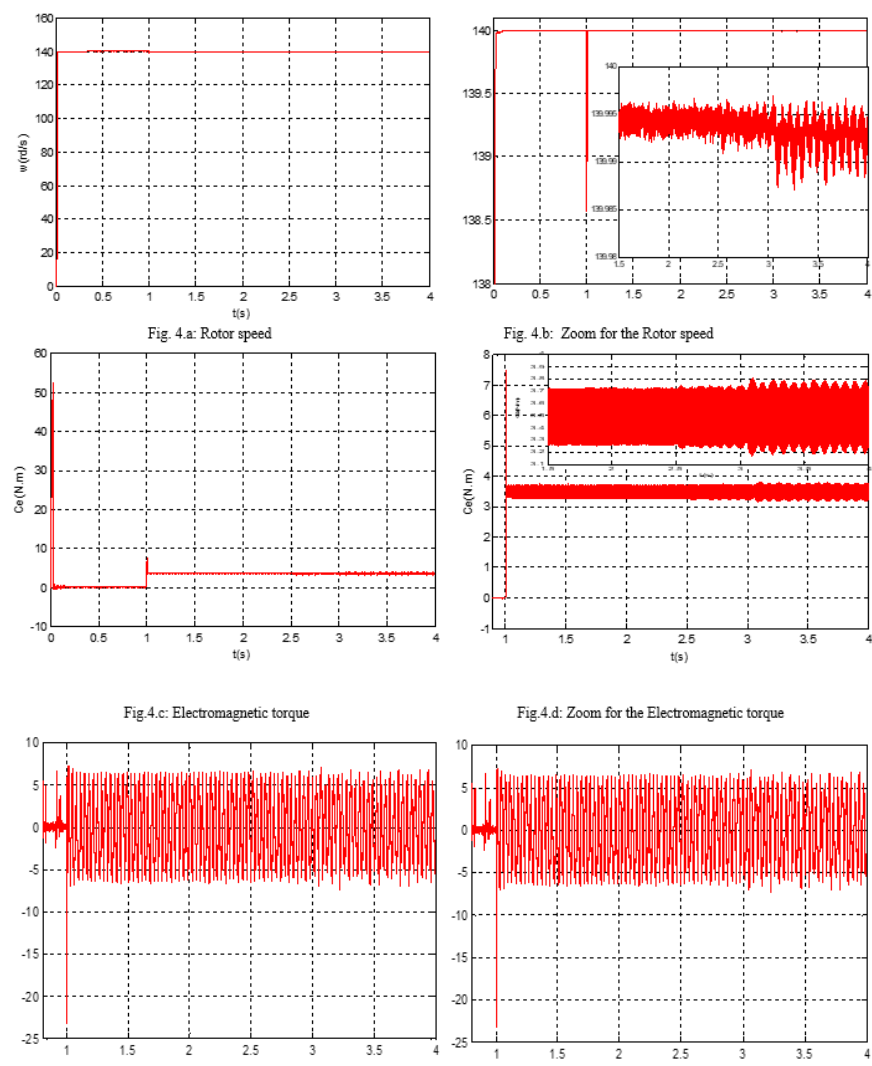

Fig.4.e: The Stator current

Fig.4.f. Zoom of Stator current

Figure 4. Simulated results FT2SMC controllers of IM without rotor defects

The simulation results are discussed, and shown in this way: it is important to notice the degradation of the speed tracking with PI method in steady state after the fault occurrence, however when using the proposed controller of fuzzy type-2sliding mode controller rotor speed oscillations are hidden(check fig 4.a), on the other hand fuzzy type-2-sliding mode controller reduces the torque oscillation considerably (check fig 4.b), it can be seen from these simulation results, that the fuzzy type-2-sliding mode controller guarantees satisfactory robustness against the broken bars, while the PI is not able to master the unbalanced machine properly, in addition to all the previous mentioned, the tracing errors converge quickly and the robust control characteristics of the fuzzy type-2-sliding mode controller system under the occurrence of uncertainties are clearly Observed. Finally, the influence of the broken bars is less effecting in fuzzy type-2sliding mode controller being compared to the PI controller.

\section{CONCLUSION}

In this paper, a new fuzzy type-2-sliding mode controller with broken bar has been presented. It was applied to improve the speed response, to reduce the overshot of a PI controller and also to avoid chattering in steady-state of a conventional sliding mode controller which causes unacceptable vibration stress of the load. With the proposed fuzzy type-2-sliding mode controller, the main goals of a well-tuned system such as, the disturbance rejection, and also the minimizing of the overshoot have been obtained. The simulation results obtained have confirmed the very good dynamic performance and robustness of the fuzzy logic type-2-sliding mode controller during the transient period and during the sudden loads. It is concluded that the proposed intelligent controller has shown superior performance than that of the parameter fixed PI controller and earlier proposed system. The FL2SMC performs a good reduction of the chattering effect, rapid time response error and a good tracking reference speed.

\section{REFERENCES}

[1] Utkin VI. (1977). Variable structure systems with sliding modes. IEEE Transactions on Automatic Control AC22(2): https://doi.org/10.1109/TAC.1977.1101446

$212-222$.

[2] Gameel GK, Areed FF, Abdalla ME. (2015). Sliding mode control for speed of an induction motor with backlash. International Journal of Applications 125(6): 54-58. https://doi.org/10.5120/ijca2015905943

[3] Belhamdi S, Goléa A. (2011). Sliding mode control of asynchronous machine presenting defective rotor bars. AMSE Journals, Series Advances C 66(1/2): 39-49.

[4] Yu XH, Kaynak O. (2009). Sliding mode control with soft computing: A survey. IEEE Transactions on Industrial Electronics 56(9): 3275-3285. https://doi.org/10.1109/TIE.2009.2027531

[5] Cipertino F, Lattanzi A, Salvatore L. (2000). Sliding mode control of an induction motor. Power Electronics and Variable Speed Drives 475: 206-210. https://doi.org/10.1049/cp:20000246

[6] Belhamdi S, Goléa A. (2017). Direct field-oriented control using fuzzy logic type-2 for induction motor with broken bars. AMSE Journals, Advances C 72(4): 203212.

[7] Mendel JM, John RI, Liu F. (2006). Interval type-2 fuzzy logic systems made simple. IEEE Transactions on Fuzzy 
https://doi.org/10.1109/TFUZZ.2006.879986

[9] Hagras H. (2007). Type-2 FLCs, A new generation of fuzzy controllers. IEEE Computational Intelligence Magazine 2:

$30-43$. https://doi.org/10.1109/mci.2007.357192

[10] Mamdani E, Assilian S. (1975). An experiment in linguistic synthesis with a fuzzy logic controller. International Journal of Machine Studies 7(1): 1-13. https://doi.org/10.1016/S0020-7373(75)80002-2

[11] Belhamdi S, Goléa A. (2013). Fuzzy logic control of asynchronous machine presenting defective rotor bars. AMSE Journals, Advances C 68(2): 54-63.

[12] Belhamdi S, Goléa A. (2015). Direct torque control for induction motor with broken bars using fuzzy logic type2. AMSE Journals, Advances C 70(1-2): 15-28.

[13] Kumar RS, Kumar KV, Ray KK. (2009). Sliding mode control of induction motor using simulation approach. IJCSNS 9(10): 93-104.

[14] Belhamdi S, Goléa A. (2017). Fuzzy sliding mode speed controller design of induction motor drives with broken bars. AMSE Journals, Advances C 72(4): 281-291.

\section{NOMENCLATURE}

\begin{tabular}{|l|l|}
\hline Abbreviations & Designation \\
\hline FL2SMC & Fuzzy Logic Type-2 sliding mode Controller \\
\hline SMC & sliding mode control \\
\hline IM & Induction Motor \\
\hline ds-qs & $\begin{array}{l}\text { Stationary reference frame direct and } \\
\text { quadrature axes }\end{array}$ \\
\hline
\end{tabular}

\begin{tabular}{|l|l|}
\hline Type-2 FLC & type-2 Fuzzy Logic Controllers \\
\hline PWM & Pulse Width Modulation \\
\hline RFL2 & Regulator Fuzzy Logic type-2 \\
\hline Vs & Stator voltage \\
\hline Is, Ir & Stator and rotor current \\
\hline $\mathrm{Ls}, \mathrm{Lr}, \mathrm{Lm}$ & Stator, rotor and mutual inductance \\
\hline$\Omega \mathrm{r}$ & the rotor angular speed \\
\hline $\mathrm{Ce}$ & Electromagnetic torque \\
\hline$\Phi s, \Phi r$ & Stator and rotor flux \\
\hline $\mathrm{Rs}, \mathrm{Rr}$ & Stator and rotor resistances \\
\hline$\Theta s$ & Angle between stator and rotor flux \\
\hline $\mathrm{p}$ & Number of pole pairs \\
\hline
\end{tabular}

\section{APPENDIX}

The parameters of the machine used for simulation are listed below [13]:

\begin{tabular}{|l|l|}
\hline $\begin{array}{l}\text { Resistance of stator and rotor } \\
\mathrm{Rs}=7.58 \Omega, \mathrm{Rr}=6.3 \Omega\end{array}$ & $50(\mathrm{~Hz})$ Stator frequency \\
\hline $\begin{array}{l}\mathrm{Ns}=160 \mathrm{Number} \text { of turns per } \\
\text { stator phase }\end{array}$ & $\mathrm{Nr}=16$ Number of rotor bars \\
\hline $\mathrm{J}=0.0054\left(\mathrm{Kgm}^{2}\right)$ Inertia & $\mathrm{p}=2$ Poles number \\
\hline $\begin{array}{l}\mathrm{R}_{\mathrm{b}}=0.00015(\Omega) \text { Resistance of a } \\
\text { rotor bar }\end{array}$ & $\begin{array}{l}\mathrm{R}_{\mathrm{e}}=0.00015(\Omega) \text { Resistance } \\
\text { of end ring segment }\end{array}$ \\
\hline $\begin{array}{l}\mathrm{L}_{\mathrm{e}}=0.1 \mathrm{e}-6(\mathrm{H}) \text { Leakage } \\
\text { inductance of end ring }\end{array}$ & $\begin{array}{l}\mathrm{L}_{\mathrm{b}}=0.1 \mathrm{e}-6 \mathrm{H} \text { Rotor bar } \\
\text { inductance }\end{array}$ \\
\hline $\mathrm{L}=65(\mathrm{~mm})$ Length of the rotor & $\begin{array}{l}\mathrm{E}=25(\mathrm{~mm}) \text { Air-gap mean } \\
\text { diameter }\end{array}$ \\
\hline $\begin{array}{l}\mathrm{L} 1 \mathrm{~s}=0.0265(\mathrm{H}) \text { Mutual } \\
\text { inductance }\end{array}$ & $\mathrm{P}=1.1(\mathrm{~kW})$ Output power \\
\hline
\end{tabular}

